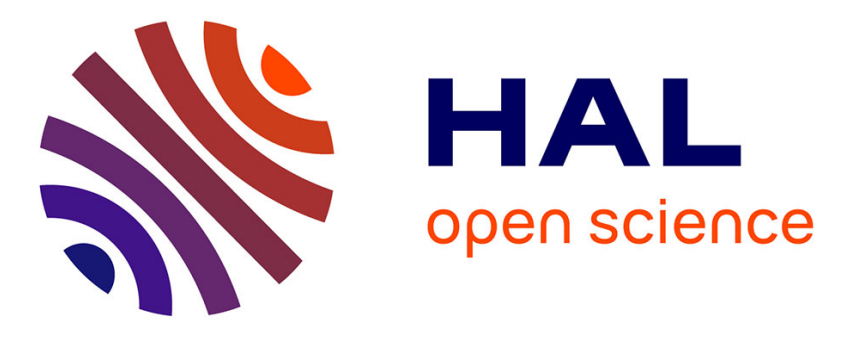

\title{
Facile synthetic route towards nanostructured Fe-TiO2(B), used as negative electrode for Li-ion batteries
}

Remi Grosjean, Marcus Fehse, Stéphanie Pigeot-Remy, Lorenzo Stievano, Laure Monconduit, Sophie Cassaignon

\section{To cite this version:}

Remi Grosjean, Marcus Fehse, Stéphanie Pigeot-Remy, Lorenzo Stievano, Laure Monconduit, et al.. Facile synthetic route towards nanostructured $\mathrm{Fe}-\mathrm{TiO} 2(\mathrm{~B})$, used as negative electrode for Li-ion batteries. Journal of Power Sources, 2015, 278, pp.1-8. 10.1016/j.jpowsour.2014.12.032 . hal-01096250

\section{HAL Id: hal-01096250 \\ https://hal.science/hal-01096250}

Submitted on 18 Dec 2014

HAL is a multi-disciplinary open access archive for the deposit and dissemination of scientific research documents, whether they are published or not. The documents may come from teaching and research institutions in France or abroad, or from public or private research centers.
L'archive ouverte pluridisciplinaire HAL, est destinée au dépôt et à la diffusion de documents scientifiques de niveau recherche, publiés ou non, émanant des établissements d'enseignement et de recherche français ou étrangers, des laboratoires publics ou privés. 


\section{Facile synthetic route towards nanostructured $\mathrm{Fe}-\mathrm{TiO}_{2}(\mathrm{~B})$, used as negative electrode for Li-ion batteries}

Remi Grosjean ${ }^{1,2,3,4}$, Marcus Fehse ${ }^{1}$, Stéphanie Pigeot-Remy ${ }^{2,3,4}$, Lorenzo Stievano ${ }^{1,5}$,Laure Monconduit $^{1,5}$, Sophie Cassaignon ${ }^{* 2,3,4,5}$

${ }^{1}$ ICG/AIME (UMR 5253 CNRS), Université Montpellier II CC 15-02, Place E. Bataillon, 34095 Montpellier Cedex 5, France.

${ }^{2}$ Sorbonne Universités, UPMC Univ. Paris 06, UMR 7574 Chimie de la Matière Condensée de Paris, 75231 Paris Cedex 05, France

${ }^{3}$ CNRS, UMR 7574, Chimie de la Matière Condensée de Paris, France ${ }^{4}$ Collège de France, UMR 7574, Chimie de la Matière Condensée de Paris, France

${ }^{5}$ Réseau sur le Stockage Electrochimique de l'Energie (RS2E), FR CNRS 3459, France.

* Corresponding author: Sophie Cassaignon

Tel: 331442715 45. E-mail: sophie.cassaignon@upmc.fr

Keywords: $\mathrm{TiO} 2(\mathrm{~B}), \mathrm{Fe}_{-} \mathrm{TiO}_{2}(\mathrm{~B})$, microwave synthesis, Li-ion batteries, scale-up 
Abstract

We present here a novel simple method for the synthesis of highly pure $\mathrm{TiO}_{2}(\mathrm{~B})$. The fast microwave-assisted synthetic route allows facile scale-up of the process. Aiming at an application of the titania polymorph as negative electrode for Li-ion batteries, we have prepared a Fe-containing $\mathrm{TiO}_{2}(\mathrm{~B})$ and tested the electrochemical performances of both pure and $\mathrm{Fe}$-containing materials. $\mathrm{Fe}$ insertion in $\mathrm{TiO}_{2}(\mathrm{~B})$ allows enhancing capacity and rate capability. 


\section{Introduction}

Making technologies such as electric vehicles or grid storage viable calls for efficient energy storage devices. Among these, Li-ion batteries, developed in the 90's, have been a revolution for the portable electronic devices field: their energy density is superior to that of conventional batteries by a factor 2 to 3 [1-3]. The Li-ion technology nowadays represents a

$\$ 11.7$ billion market, and is still growing [2]. Despite this commercial success and high energy density, the current device generation has relatively poor power output properties compared to other energy storage systems such as supercapacitors, which on the other hand present very small energy densities [4]. For high-power applications, a compromise between high energy density and power output might be interesting. This is where materials with pseudocapacitive behavior [5-7], such as titanium dioxide $\mathrm{TiO}_{2}(\mathrm{~B})$, find an interest.

Among potential candidates to replace the commonly used carbon graphite as anode material, also titanium-based materials, such as titanate spinel $\mathrm{Li}_{4} \mathrm{Ti}_{5} \mathrm{O}_{12}$ or the different polymorphs of titanium dioxide, have been investigated [8-12]. Among the latters, $\mathrm{TiO}_{2}(\mathrm{~B})$ appears as very promising. Indeed, it exhibits low toxicity, is cost effective and has very good rate capability and safety (because of its higher lithiation potential, $1.6 \mathrm{~V}$ vs. $\mathrm{Li} / \mathrm{Li}^{+}$, compared to that of graphite, $0.1 \mathrm{~V}$ vs. $\mathrm{Li} / \mathrm{Li}^{+}$) [13]. When compared to other polymorph, titania bronze exhibits the highest capacity $(335 \mathrm{mAh} / \mathrm{g}$, compared to $170 \mathrm{mAh} / \mathrm{g}$ for brookite, $250 \mathrm{mAh} / \mathrm{g}$ for rutile and $285 \mathrm{mAh} / \mathrm{g}$ for anatase) [13]

Though, the main interest of $\mathrm{TiO}_{2}(\mathrm{~B})$ lies in its pseudocapacitive behavior towards insertion of lithium ion [13-16]. Recent studies make the surface structure responsible for this substantial $\mathrm{Li}^{+}$uptake. For high specific area materials with strained morphology (such as nanotubes or nanowires), surface sites are quickly filled during the first part of discharge, 
followed by the insertion of the absorbed ions into the interior of the material through radial pathways connecting the different insertion sites [17]. However, the origin of this enhanced high power cycling is still subject to debate. First synthesized in 1980 by Marchand et al. [18] with solid chemistry methods, $\mathrm{TiO}_{2}(\mathrm{~B})$ is a metastable phase that transforms into anatase above $550^{\circ} \mathrm{C}$ at atmospheric pressure. The first synthesis of nanostructured $\mathrm{TiO}_{2}(\mathrm{~B})$ has been reported by Kasuga and co-workers in 1999 [19]. The classical approach is hydrothermal synthesis in strong alkaline conditions using variety of different starting materials $\left(\mathrm{TiO}_{2}[12]\right.$, $\mathrm{TiCl}_{4}$ [9], Tetrabutyl titanate [20]). Under such severe conditions, the isomorphous alkali titanate precipitates. Subsequent ion exchange and calcination at relatively low temperatures are used to remove the alkali ions and to obtain the bronze polymorph. Preparation of $\mathrm{TiO}_{2}(\mathrm{~B})$ by this route raises several problems: first, its metastability impedes high pressures or temperatures during synthesis or calcination. Therefore, even if the synthesis is performed at low temperature, anatase impurities cannot be avoided in the final product [21]. The presence of such impurities is difficult to detect through simple X-ray Diffraction (XRD) analysis but are efficiently revealed by Raman spectroscopy and galvanostatic cycling (anatase shows a characteristic plateau at $1.8 \mathrm{~V}$ ). Secondly, long hydrothermal syntheses are not viable for many applications (reducing synthesis time reduces the yield). Therefore, microwave-assisted synthetic methods are an interesting alternative as they have proven to be energy efficient, cost effective and quicker than classical hydrothermal methods for the production of anatase [22].

Inorganic materials often have enhanced performance when containing aliovalent cations. Notably, for other $\mathrm{TiO}_{2}$ polymorphs, cation insertion has proven to be an efficient technique to increase their low intrinsic conductivity [23]. When it comes to $\mathrm{TiO}_{2}(\mathrm{~B})$, cation insertion has already been performed and its effect on magnetic and photocatalytic properties 
studied. Only very recently it has been shown that $\mathrm{Nb}$-insertion has positive effect on tap density and microstructure of $\mathrm{TiO}_{2}(\mathrm{~B})$, leading to higher Li storage capacity [24].

In this study, we report a novel soft chemistry synthesis of phase-pure $\mathrm{TiO}_{2}(\mathrm{~B})$ by hydrothermal synthesis and microwave-assisted synthesis, which allowed us to reduce the reaction time by over $95 \%$. We also demonstrate the potential of the incorporation of thirdparty element (here iron) in titania bronze to improve its electrochemical cycling properties. We have chosen iron in order to improve the electrical conductivity of the final material. Notably, the high atomic percentage of iron used (ca. 10\%) makes this incorporation difficult to describe as actual doping. The insertion method was also successfully extended to other cations such as $\mathrm{Cu}^{2+}, \mathrm{Mn}^{2+}, \mathrm{Nb}^{5+}, \mathrm{W}^{6+}$, which were not discussed here.

Crystallinity and phase composition of the synthesized materials were characterized by XRD, and the phase purity was confirmed by Raman spectroscopy. Size and morphology of the nanoparticles were analyzed through Transmission Electronic Microscopy (TEM). The efficiency of the Fe-insertion procedure was analyzed by ${ }^{57} \mathrm{Fe}$ Mössbauer spectroscopy. Li-ion intercalation properties were tested by galvanostatic cycling at different cycling rates.

\section{Experimental}

\subsection{Synthesis}

Phase-pure $\mathrm{TiO}_{2}(\mathrm{~B})$

Hydrothermal synthesis

$1.0 \mathrm{~g}$ of titania (PC500) was mixed with $75 \mathrm{~mL}$ of an aqueous solution of $\mathrm{KOH}$ (15 mol. $\left.\mathrm{L}^{-1}\right)$ under constant stirring. The resulting white suspension was kept under vigorous 
stirring for $30 \mathrm{~min}$ before alternating stirring and dispersion in an ultrasonic bath ( 5 min each) during $30 \mathrm{~min}$. The resulting white solution was transferred to Teflon-lined autoclaves and kept at $150{ }^{\circ} \mathrm{C}$ for $72 \mathrm{~h}$. The resulting white product was washed with deionized water until the $\mathrm{pH}$ of the supernatant was lower than 12 . Then, the filtered solid was stirred with an aqueous solution of $\mathrm{HCl}\left(0.1 \mathrm{~mol} . \mathrm{L}^{-1}\right)$ for $4 \mathrm{~h}$ to exchange the intercalated $\mathrm{K}^{+}$for protons. Subsequently, the solid was washed again with deionized water until the $\mathrm{pH}$ of the supernatant was higher than 5 and then dried at $70{ }^{\circ} \mathrm{C}$ for $15 \mathrm{~h}$ to produce hydrogen titanate.

The resulting white solid was finally annealed at $400{ }^{\circ} \mathrm{C}$ for $3 \mathrm{~h}$ to obtain pure titania. The procedure was successfully scaled-up by a factor of 3 . The typical yield is above $95 \%$ (950 mg).

Microwave-assisted synthesis

Phase-pure titania bronze was also obtained using microwave-assisted heating. The experimental procedure was similar to hydrothermal conditions except for heating step. The suspension of titania in 15 mol. $\mathrm{L}^{-1} \mathrm{KOH}$ was transferred to Teflon microwave tubes and kept at $150{ }^{\circ} \mathrm{C}$ for $3 \mathrm{~h}$. The following steps were identical to those of hydrothermal synthesis. The procedure could also be successfully scaled-up by a factor of 3 .

Fe-containing $\mathrm{TiO}_{2}(\mathrm{~B})$

During the initial synthesis step, $0.506 \mathrm{~g}$ of $\mathrm{Fe}\left(\mathrm{NO}_{3}\right)_{3} \cdot 9 \mathrm{H}_{2} \mathrm{O}$ (corresponding to a $\mathrm{Fe} / \mathrm{Ti}$ atomic ratio of 0.1 ) was added to the dispersion of titania in $15 \mathrm{~mol} . \mathrm{L}^{-1} \mathrm{KOH}$ under constant stirring. Alternative stirring and ultrasonic dispersion were carried out again ( $5 \mathrm{~min}$ each, for a 
total of $30 \mathrm{~min}$ ). For hydrothermal synthesis and microwave-assisted synthesis the following synthetic steps were identical to those used for synthetizing pure $\mathrm{TiO}_{2}(\mathrm{~B})$.

These experimental procedures are summarized in the flowchart in Figure 1.

Figure 1. Flowchart of the synthetic methods to obtain pure and $\mathrm{Fe}$-containing $\mathrm{TiO}_{2}(\mathrm{~B})$

\subsection{Electrochemical tests}

The titania powder was sieved using a $50 \mu \mathrm{m}$ mesh sieve, and intimately mixed with carbon black (Y50A) and PolyViniliDene Fluoride (PVdF) in a weight ratio of $77: 8: 15$, respectively. The homogeneous slurry obtained by addition of N-methyl-2pyrrolidone (NMP) was tape casted on a roughened copper foil (provided by Schlenk Metalfolien, for enhanced adhesion) using a doctor blade system, to obtain $20 \mu \mathrm{m}$ thick films. The punched-out disks were used as the working electrodes.

The working electrodes were assembled in Swagelok ${ }^{\mathrm{TM}}$ cells. Metallic lithium was used as reference and counter electrode. Whatman glass-fiber was used as the separator and impregnated with the electrolyte, a solution of $1 \mathrm{M} \mathrm{LiPF}_{6}$ in a mixture of ethylene carbonate, propylene carbonate and dimethyl carbonate in a weight ratio $1: 1: 3$. Since both metallic lithium and the electrolyte are sensitive to air and moisture, the device was assembled in a glove-box under argon atmosphere.

As-built devices were tested in galvanostatic mode at different cycling rates, from $\mathrm{C} / 10$ to $5 \mathrm{C}$, where $\mathrm{C} / \mathrm{n}$ corresponds to a current for which one mole of lithium ion is inserted per mole of $\mathrm{TiO}_{2}$ in $\mathrm{n}$ hours. 


\subsection{Characterization}

A Synthos 3000 microwave oven (Anton France) was used for heating the suspensions under microwave irradiation. Powder XRD analyses were performed with a Bruker D8 X-ray diffractometer operating in the Brag-Brentano reflection mode equipped with a nickel filter to select the $\mathrm{Cu}-K_{\alpha}$ radiation. The data were collected in the $2 \theta=10^{\circ}-70^{\circ}$ range with $0.05^{\circ}$ steps. Pattern analyses were performed using the ICDD DD View PDF-4+ 2009 RDB base, (JCPDS 00-021-1272, 00-021-1276 and 00-46-1238 for anatase, rutile and $\mathrm{TiO}_{2}(\mathrm{~B})$, respectively).

The morphology and the average particle size of the samples were analyzed by TEM using a Tecnai spirit G2 apparatus equipped with a Gatan CCD camera and operating at $120 \mathrm{kV}\left(\mathrm{LaB}_{6}\right)$. Carbon-coated copper grids were used as sample holders. High resolution TEM (HRTEM) and STEM EDX mapping were performed at $200 \mathrm{kV}$ using a Jeol $2100 \mathrm{~F}$ apparatus $\left(\mathrm{LaB}_{6}\right)$.

Raman spectra were recorded using a LabRarm ARAMIS IR ${ }^{2}$ (Horiba Jobin Yvon) spectrometer with a helium neon laser working at $633 \mathrm{~nm}$.

Specific surface areas were measured by $\mathrm{N}_{2}$ physisorption at $77 \mathrm{~K}$ using a Belsorb Max instrument. The Brunauer-Emmett-Teller (BET) method was applied to calculate the specific surface area. Electrochemical cycling was carried out in galvanostatic mode on a Biologic multichannel potentiostat.

57

Fe transmission Mössbauer spectroscopy data were recorded in the constant acceleration mode with a ${ }^{57} \mathrm{Co}: \mathrm{Rh}$ source. During the measurements, the source was always 
kept at room temperature whereas the temperature of the sample was varied between $4.5 \mathrm{~K}$ and room temperature using a Helium gas-flow cryostat. The velocity scale was calibrated with the magnetically split sextet spectrum of a high-purity $\alpha$-Fe foil as the reference absorber. The spectra of Fe-containing $\mathrm{TiO}_{2}(\mathrm{~B})$ were fitted to appropriate combination of Lorentzian profiles by least-squares methods using the computer program Isofit [25]. In this way, spectral parameters such as quadrupole splitting $(\Delta)$, isomer shift $(\delta)$, linewidth $(\Gamma)$ and relative resonance areas of the different spectral components were determined. The isomer shifts are given relative to $\alpha-\mathrm{Fe}$ metal.

\section{Results and discussion}

\subsection{Synthesis}

Hydrothermal synthesis

The synthetic method used allows facile and efficient synthesis of phase-pure $\mathrm{TiO}_{2}(\mathrm{~B})$ with high yields. This method is a modification of that developed by Kasuga and co-workers [19]. The main modification lies in the nature of the alkaline solution used $\left(15 \mathrm{~mol} . \mathrm{L}^{-1} \mathrm{KOH}\right.$ in our case). We tested different solid precursors (Cristal PC500 $\mathrm{TiO}_{2}$, Evonik P25 $\mathrm{TiO}_{2}$ or lab synthesized anatase [22] and rutile [11]). We noticed that when the precursors contain rutile, insufficient alkaline treatment leads to rutile impurities in the final product. The suspension is then submitted to thermal treatment in autoclaves under self-generated pressure conditions ( $180{ }^{\circ} \mathrm{C}$ for 3 days). Reduction of the reaction time simply leads to lower synthetic yields (for this method, yield is over $95 \%$ ). The alkaline titanate obtained in this step is then subjected to ionic exchange to exchange the alkaline ions in the interlayer space for protons. This step can be performed with several methods, using $\mathrm{HCl}$ or $\mathrm{HNO}_{3}$, in a concentration 
range from 0.1 to 1 mol. $\mathrm{L}^{-1}$, for 4 to 24 hours. In our case, this exchange is performed by dispersion of the alkaline titanate in $\mathrm{HCl}\left(0.1 \mathrm{~mol} . \mathrm{L}^{-1}\right)$ for $4 \mathrm{~h}$. A final calcination step leads to dehydration and condensation of the layered titanic acid to obtain $\mathrm{TiO}_{2}(\mathrm{~B})$.

Figure 2. XRD patterns for pure and $\mathrm{Fe}$-containing $\mathrm{TiO}_{2}(\mathrm{~B})$, synthesized under hydrothermal conditions (a) and for microwave-assisted syntheses (b). All patterns are plotted vs. the reference for $\mathrm{TiO}_{2}(\mathrm{~B})$, black sticks.

The XRD of the final product is in good agreement with reference patterns for $\mathrm{TiO}_{2}$ (B) (JCPDS \# 00-46-1238 for $\mathrm{TiO}_{2}(\mathrm{~B})$ ) (Figure 2). However the low crystallinity observed by XRD demands further characterization to confirm the purity of the synthesized phase. As previously reported [26], anatase-to- $\mathrm{TiO}_{2}(\mathrm{~B})$ ratio in mixed phases can be easily determined using Raman spectroscopy, even at low crystallization level.

Figure 3. Raman spectra of pure and Fe-containing $\mathrm{TiO}_{2}(\mathrm{~B})$, synthesized under hydrothermal conditions (a) and for microwave-assisted synthesis (b)

High purity of the obtained phase was confirmed by this technique, as no peak corresponding to anatase can be seen on the spectrum (Figure 3, main peaks positions for anatase $\left(144,398,518\right.$, and $\left.639 \mathrm{~cm}^{-1}\right)$. However, whether the high yield in $\mathrm{TiO}_{2}(\mathrm{~B})$ phase, meaning higher phase stability, is due to the reduced hardness of $\mathrm{K}^{+} \mathrm{vs}$. $\mathrm{Na}^{+}$and/or to the increased size of $\mathrm{K}^{+}$imposing steric constraints favoring the formation of the layered titanate phase cannot be answered with certainty at this point.

The morphology of the particles and their size distribution was analyzed by transmission electronic microscopy (TEM). Nanoparticles are single crystals (Figure 4) and, 
in agreement with previous studies [12,27], they have a nanorod morphology, probably formed from rolled nanosheets, which width is in the 5-9 nm range and length up to $100 \mathrm{~nm}$. Analysis of micrographs shows lattice fringes with distances of $6.24 \AA$, corresponding to the [001] interlayer spacing along the nanorods of $\mathrm{TiO}_{2}(\mathrm{~B})$. That is possibly consistent with previous studies that report morphology retention along the synthetic path (from alkaline titanate to titania bronze)[28] and the $c$ axis perpendicular to the rods, at least until the titanic acid intermediate [29]. These results are confirmed by electron diffraction (not shown), which does not show any signal typical of anatase or of other titania polymorphs in the diffraction patterns. This result confirms the high phase purity of the final product.

Microwave synthesis

As highlighted by previous studies, formation of metastable $\mathrm{TiO}_{2}(\mathrm{~B})$ is strongly dependent on synthesis parameters such as the reaction time, making the synthesis of $\mathrm{TiO}_{2}(\mathrm{~B})$ with microwave-assisted processes by no means evident. The synthetic route previously described was tested with an alternate heating mode, under microwave irradiation. $\mathrm{TiO}_{2}(\mathrm{~B})$ was successfully obtained in this way. At this point, the different characterization techniques used exhibit no significant differences between microwave-assisted and classic hydrothermal syntheses neither by XRD (Figure 2) nor by Raman spectroscopy (Figure 3). As an example, Figure 4 shows TEM images of the particles obtained under hydrothermal conditions. Microwave synthesis allows subsequent reduction of the reaction time by about $95 \%$, increases cost-effectiveness (by reducing energy consumption) of the synthesis and allows an easier scale-up of the synthesis.

Figure 4. TEM micrographs for pure $\mathrm{TiO}_{2}(\mathrm{~B})(\mathrm{a})$ and $\mathrm{Fe}$-containing $\mathrm{TiO}_{2}(\mathrm{~B})(\mathrm{b})$ synthesized under hydrothermal conditions. 
Fe-containing $\mathrm{TiO}_{2}(\mathrm{~B})$

A Fe precursor was added to the initial dispersion of anatase in $\mathrm{KOH}$ to obtain $\mathrm{Fe}$ containing $\mathrm{TiO}_{2}(\mathrm{~B})$. The following synthetic steps were identical to those performed in the case of phase-pure $\mathrm{TiO}_{2}(\mathrm{~B})$. This synthetic methodology was also successfully applied to $\mathrm{Cu}^{2+}, \mathrm{Mn}^{2+}, \mathrm{Nb}^{5+}$ or $\mathrm{W}^{6+}$ cations (not shown). We also successfully transposed the synthetic path for Fe-containing $\mathrm{TiO}_{2}(\mathrm{~B})$ to microwave-assisted synthesis. The final powders have an ochre-like coloration, and the UV-Vis absorption spectra of the Fe-containing samples exhibit an additional peak around $485 \mathrm{~nm}$ (Figure 5) which is in line with Fe insertion in the $\mathrm{TiO}_{2}$. According to XRD (Figure 2), samples obtained by both heating modes are very similar as for phase-pure titania bronze. XRD patterns do not exhibit new peaks, nor shift of $\mathrm{TiO}_{2}(\mathrm{~B})$ peaks. This result rules out the presence of additional crystalline phases such as iron oxides, but not of additional Fe-containing amorphous phases.

Figure 5. UV/VIS spectra without $\mathrm{Fe}^{3+}(a)$ and $(b)$ with $\mathrm{Fe}^{3+}$ synthesized under hydrothermal conditions

In order to gather more information on the chemical state of the iron in these samples, they were studied by ${ }^{57} \mathrm{Fe}$ Mössbauer spectroscopy both at room temperature and at $4.5 \mathrm{~K}$. The spectra at both temperatures of the sample obtained by hydrothermal synthesis are shown in Figure 6. Both spectra show a single paramagnetic doublet with hyperfine parameters typical of trivalent iron in the octahedral coordination. The similarity of the two spectra, and the lack of magnetically split components at low temperature are in line with the absence of iron oxides in the samples. In fact, nanosized iron oxides usually show a superparamagnetic 
behavior at room temperature, thus leading to a simple doublet in the Mössbauer spectrum which could be confused with that of $\mathrm{Fe}$ atoms incorporated in the $\mathrm{TiO}_{2}$ lattice. At liquid helium temperature, however, even very small iron oxide nanoparticles are expected to be largely below the blocking temperature, giving rise to a magnetic hyperfine splitting, i.e., to a hyperfine magnetic sextet, in the Mössbauer spectrum. The lack of magnetic ordering at low temperature observed in our case is thus in line with the absence of any kind of more or less crystalline iron oxide, and confirms that the iron atoms are most probably incorporated in the $\mathrm{TiO}_{2}(\mathrm{~B})$ lattice.

Figure 6. Mössbauer ${ }^{57} \mathrm{Fe}$ spectra of $\mathrm{Fe}$-containing $\mathrm{TiO}_{2}(\mathrm{~B})$, synthesized under hydrothermal conditions, measured at 295 and $4.5 \mathrm{~K}$.

TEM micrographs show the same characteristic distances as in pure $\mathrm{TiO}_{2}(\mathrm{~B})$. The Raman spectrum (Figure 3) exhibits a peak intensity increase in the case of Fe-containing samples, especially in the $220-250 \mathrm{~cm}^{-1}$ area, which origin could not be attributed yet. No new band, however, could be identified in the Raman spectra of iron containing samples. Moreover TEM-EDX mapping analyses clearly showed a perfect homogeneous repartition of $\mathrm{Fe}$ in the $\mathrm{TiO}_{2}$ sample (for HT and MW samples) which not only demonstrates the presence of iron in the final product, but also is in line with the homogeneous incorporation of iron in the lattice of $\mathrm{TiO}_{2}$ (B) (Figure 7).

Figure 7. STEM-EDX for Fe-containing $\mathrm{TiO}_{2}(B)$ synthesized under hydrothermal conditions, elemental maps for Ti, $O$ and $F e$. 
In conclusion, Mössbauer spectroscopy, UV and SEM are in perfect agreement and show that, for the hydrothermal as well as for the microwave-assisted samples, a single Fe containing phase is present.

\subsection{Electrochemistry}

Both samples were tested at several cycling rates, from $\mathrm{C} / 10$ to $5 \mathrm{C}$. For both samples (with or without iron), classic hydrothermal synthesis or microwave-assisted synthesis, were electrochemically tested in lithium batteries. For all samples, galvanostatic curves show no plateau at $1.8 \mathrm{~V}$, which is characteristic of the anatase phase (Figure 6). This confirms the phase-purity of the synthesized samples and a monophasic insertion mechanism for $\mathrm{TiO}_{2}(\mathrm{~B})$, without phase transformation throughout cycling [24,30]. Furthermore for all curves the first cycles are quite similar confirming the absence of iron oxide active phase vs Li.

The samples were cycled 5 or 10 cycles at subsequently increased cycling rate as presented in Figure 8. For all samples, the capacity decreases when the cycling rate increases. Note that the offset between charge and discharge at low cycling rates $(\mathrm{C} / 10$, Figure 8 , or lower, not shown) which is attributed to parasite reactions of the electrolyte cannot be seen at higher cycling rate. This phenomenon is most likely linked to the electrolyte degradation processes slower than the $\mathrm{Li}^{+}$insertion in $\mathrm{TiO}_{2}$. Galvanostatic curves evidence a higher coulombic efficiency at increased cycling rates, which is consistent with the pseudocapacitive behavior of $\mathrm{TiO}_{2}(\mathrm{~B})$ and with presence of secondary processes which are kinetically limited. Both significant irreversible capacity upon first discharge and systematic higher capacity on discharge than on charge in further cycling are observed for all samples. These phenomena are much more enhanced for HT samples than for MW samples whereas the surface area of the HT powder $\left(260 \mathrm{~m}^{2} \cdot \mathrm{g}^{-1}\right)$ is the same than the MW one $\left(267 \mathrm{~m}^{2} \cdot \mathrm{g}^{-1}\right)$. These findings are in 
agreement with studies stating reduction potential of EC, DMC and PC in the range of 0.9-

$1.3 \mathrm{~V}[31,32]$.

These reactions might also be linked to the intrinsic nature of this material. On the one hand, $\mathrm{TiO}_{2}$ features well-known catalytic properties, which can lead to destabilization of electrolytes, and on the other hand, the $\mathrm{TiO}_{2}$ surface carries always chemi- and/or physisorbed $\mathrm{H}_{2} \mathrm{O}$ and $\mathrm{OH}$ groups. Upon contact with lithium, they form irreversibly strong Ti-O-Li bonds accounting for the main part of the capacity loss upon first cycle, while the liberation of proton is likely to initiate electrolyte reduction [33].

The capacity is stable regardless of the applied cycling rates. The capacity observed for hydrothermal syntheses appears higher than that observed for microwave ones, 180 $\mathrm{mAh} / \mathrm{g}$ to $130 \mathrm{mAh} / \mathrm{g}$ for $\mathrm{HT}$, and $140 \mathrm{mAh} / \mathrm{g}$ to $100 \mathrm{mAh} / \mathrm{g}$ for MW for phase-pure $\mathrm{TiO}_{2}(\mathrm{~B})$, $230 \mathrm{mAh} / \mathrm{g}$ to $170 \mathrm{mAh} / \mathrm{g}$ for $\mathrm{HT}$ and $170 \mathrm{mAh} / \mathrm{g}$ to $125 \mathrm{mAh} / \mathrm{g}$ for MW for iron-containing $\mathrm{TiO}_{2}(\mathrm{~B})$, at $\mathrm{C} / 10$ to $5 \mathrm{C}$ cycling rate, which cannot be explained by a variation of the surface area of the powders which might enhance the surface of reaction with Li. Presumably the crystallinity of MW samples is lower than that of the HT samples, promoting the solubility of particles in the electrolyte and leading to lower columbic efficiency.

We evidence overall capacity increase up to $30 \%$ for classic hydrothermal syntheses and $15 \%$ for microwave-assisted syntheses, for iron-containing samples.

Figure 8. Galvanostatic curves of pure $\mathrm{TiO}_{2}(\mathrm{~B})(\mathrm{a})$ and (c); and $\mathrm{Fe}$-containing $\mathrm{TiO}_{2}(\mathrm{~B})(\mathrm{b})$ and $(d)$ prepared by hydrothermal and microwave-assisted synthesis respectively. 


\section{Conclusion}

We present here a simple a soft-chemistry synthesis of highly pure $\mathrm{TiO}_{2}(\mathrm{~B})$, by hydrothermal and microwave-assisted synthesis, the latter being much faster and energy efficient and therefore attractive for up-scale. By using these simple methods we succeed in the preparation of highly pure $\mathrm{Fe}$ containing $\mathrm{TiO}_{2}(\mathrm{~B})$ samples. The iron insertion in the $\mathrm{TiO}_{2}(\mathrm{~B})$ has been demonstrated by microscopy (TEM and EDX analysis) and Mössbauer spectroscopy. $\mathrm{TiO}_{2}(\mathrm{~B}) \mathrm{HT}$ and $\mathrm{MW}$ have been electrochemically tested vs Li. Former show higher capacity and rate capability than latter. This is attributed to a higher crystallinity for HT powder in comparison to MW one, which leads to ia better stability of the active material towards the electrolyte. $\mathrm{Fe}-\mathrm{TiO}_{2}(\mathrm{~B})$ samples, $\mathrm{HT}$ as well as $\mathrm{MW}$, show higher performance than $\mathrm{TiO}_{2}(\mathrm{~B})$ without $\mathrm{Fe}$, likely due to an increase of the electronic conductivity, since neither structural crystallographic nor morphologic changes have been evidenced in Fe-samples. Indeed a $230 \mathrm{mAhg}^{-1}$ capacity can be stabilized at low rate.

This work of doping of $\mathrm{TiO}_{2}(\mathrm{~B})$ is pioneering and the preliminary electrochemical results show that this way is efficient to improve the electrochemical performance in term of energy density as well as of power. These results may pave the way for a low cost and environmentally benign electrode presenting good performance in lithium battery.

\section{Acknowledgements}

The authors acknowledge José Luiz-Marie for Raman spectroscopy and Dr. Moulay Sougrati for Mössbauer spectroscopy at ICGM. Dr. David Portehault for the EDX mapping pictures taken at IMPMC is also thanked. 


\section{Figure Captions}

Figure 1. Flowchart of the synthetic methods to obtain pure and $\mathrm{Fe}$-containing $\mathrm{TiO}_{2}(\mathrm{~B})$

Figure 2. XRD patterns for pure and $\mathrm{Fe}$-containing $\mathrm{TiO}_{2}(\mathrm{~B})$, synthesized under hydrothermal conditions (a) and for microwave-assisted syntheses (b). All patterns are plotted vs. the reference for $\mathrm{TiO}_{2}(\mathrm{~B})$, black sticks.

Figure 3. Raman spectra of pure and $\mathrm{Fe}$-containing $\mathrm{TiO}_{2}(\mathrm{~B})$, synthesized under hydrothermal conditions (a) and for microwave-assisted synthesis (b)

Figure 4. TEM micrographs for pure $\mathrm{TiO}_{2}(\mathrm{~B})(a)$ and Fe-containing $\mathrm{TiO}_{2}(\mathrm{~B})(\mathrm{b})$ synthesized under hydrothermal conditions.

Figure 5. UV/VIS spectra without $\mathrm{Fe}^{3+}(a)$ and $(b)$ with $\mathrm{Fe}^{3+}$ synthesized under hydrothermal conditions

Figure 6. Mössbauer ${ }^{57} \mathrm{Fe}$ spectra of Fe-containing $\mathrm{TiO}_{2}(\mathrm{~B})$, synthesized under hydrothermal conditions, measured at 295 and $4.5 \mathrm{~K}$.

Figure 7. STEM-EDX for Fe-containing $\mathrm{TiO}_{2}(\mathrm{~B})$ synthesized under hydrothermal conditions, elemental maps for Ti, $O$ and $F e$.

Figure 8. Galvanostatic curves of pure $\mathrm{TiO}_{2}(\mathrm{~B})(\mathrm{a})$ and (c); and Fe-containing $\mathrm{TiO}_{2}(\mathrm{~B})(\mathrm{b})$ and $(d)$ prepared by hydrothermal and microwave-assisted synthesis respectively.

\section{References}

[1] J.M. Tarascon, M. Armand, Nature 414 (2001) 359.

[2] P.G. Bruce, B. Scrosati, J.-M. Tarascon, Angew. Chem. Int. Ed. Engl. 47 (2008) 2930.

[3] B. Scrosati, Nature (1995) 557.

[4] P. Simon, Y. Gogotsi, Nat. Mater. 7 (2008) 845.

[5] W. Dong, D. Rolison, B. Dunna, Electrochem. Solid-State Lett. 3 (2000) 457.

[6] J.W. Long, K.E. Swider, C.I. Merzbacher, D.R. Rolison, Langmuir 15 (1999) 780.

[7] M. Toupin, T. Brousse, D. Bélanger, Chem. Mater. 14 (2002) 3946.

[8] A.D. Robertson, L. Trevino, H. Tukamoto, J.T.S. Irvine, J. Power Sources 81-82 (1999) 352.

[9] L. Kavan, M. Kalbac, M. Zukalová, Chem. Mater. 16 (2004) 477.

[10] M.A. Reddy, M.S. Kishore, V. Pralong, U. V. Varadaraju, B. Raveau, Electrochem. Solid-State Lett. 10 (2007) A29.

[11] E. Baudrin, S. Cassaignon, M. Koelsch, J. Jolivet, L. Dupont, J.M. Tarascon, Electrochem. Commun. 9 (2007) 337.

[12] A R. Armstrong, G. Armstrong, J. Canales, P.G. Bruce, Angew. Chem. Int. Ed. Engl. 43 (2004) 2286.

[13] A.G. Dylla, G. Henkelman, K.J. Stevenson, Acc. Chem. Res. 46 (2013) 1104.

[14] M. Zukalová, M. Kalbáč, L. Kavan, I. Exnar, M. Graetzel, Chem. Mater. 17 (2005) 1248.

[15] S. Liu, H. Jia, L. Han, J. Wang, P. Gao, D. Xu, J. Yang, S. Che, Adv. Mater. 24 (2012) 3201. 
[16] H. Liu, Z. Bi, X.-G. Sun, R.R. Unocic, M.P. Paranthaman, S. Dai, G.M. Brown, Adv. Mater. 23 (2011) 3450 .

[17] M. Koudriachova, Surf. Interface Anal. 42 (2010) 1330.

[18] R. Marchand, L. Brohan, M. Tournoux, Mater. Res. Bull. 15 (1980) 1129.

[19] T. Kasuga, M. Hiramatsu, A. Hoson, T. Sekino, K. Niihara, Adv. Mater. 567 (1999) 1307.

[20] B. Zhao, F. Chen, H. Liu, J. Zhang, J. Phys. Chem. Solids 72 (2011) 201.

[21] M. Fehse, F. Fischer, C. Tessier, L. Stievano, L. Monconduit, J. Power Sources 231 (2013) 23.

[22] F. Dufour, S. Cassaignon, O. Durupthy, C. Colbeau-Justin, C. Chanéac, Eur. J. Inorg. Chem. 2012 (2012) 2707.

[23] M. Fehse, M. Ben Yahia, L. Monconduit, F. Lemoigno, M.-L. Doublet, F. Fischer, C. Tessier, L. Stievano, J. Phys. Chem. C (2014).

[24] E. Ventosa, B. Mei, W. Xia, M. Muhler, W. Schuhmann, ChemSusChem 6 (2013) 1312.

[25] W. Kündig, Nucl. Instruments Methods 75 (1969) 336.

[26] T. Beuvier, M. Richard-Plouet, L. Brohan, J. Phys. Chem. C 113 (2009) 13703.

[27] T. Beuvier, Des Nanotitanates de Sodium Aux Dioxydes de Titane : Électrode Négative À Base de TiO2(B) Nanométrique Pour Accumulateur Lithium-Ion. PhD thesis (2009), Nantes, france.

[28] R. Ma, Y. Bando, T. Sasaki, Chem. Phys. Lett. 380 (2003) 577.

[29] T. Beuvier, M. Richard-Plouet, M. Mancini-Le Granvalet, T. Brousse, O. Crosnier, L. Brohan, Inorg. Chem. 49 (2010) 8457.

[30] A. R. Armstrong, C. Arrouvel, V. Gentili, S.C. Parker, M.S. Islam, P.G. Bruce, Chem. Mater. 22 (2010) 6426.

[31] J.B. Goodenough, Y. Kim, Chem. Mater. 22 (2010) 587.

[32] X. Zhang, P.N. Ross, R. Kostecki, F. Kong, S. Sloop, J.B. Kerr, K. Striebel, E.J. Cairns, F. McLarnon, J. Electrochem. Soc. 148 (2001) A463.

[33] W.J.H. Borghols, M. Wagemaker, U. Lafont, E.M. Kelder, F.M. Mulder, J. Am. Chem. Soc. 131 (2009) 17786. 


\section{$\mathrm{TiO}_{2}+15$ mol.L $\mathrm{L}^{-1} \mathrm{KOH}$ Stirring for $30 \mathrm{~min}$}

Stirring/Ultrasonic bath, 5 min each, for $30 \mathrm{~min}$

\section{$72 \mathrm{~h}$ at $150^{\circ} \mathrm{C}$ in autoclaves}

Removal of supernatant

Washing with DI water

until $\mathrm{pH}<12$

\section{HCl 0,1 mol.L ${ }^{-1}, 4 \mathrm{~h}$}

Washing with DI water

until $\mathrm{pH}>5$

Drying, $70^{\circ} \mathrm{C}-15 \mathrm{~h}$

Annealing, $400{ }^{\circ} \mathrm{C}-4 \mathrm{~h}$ 


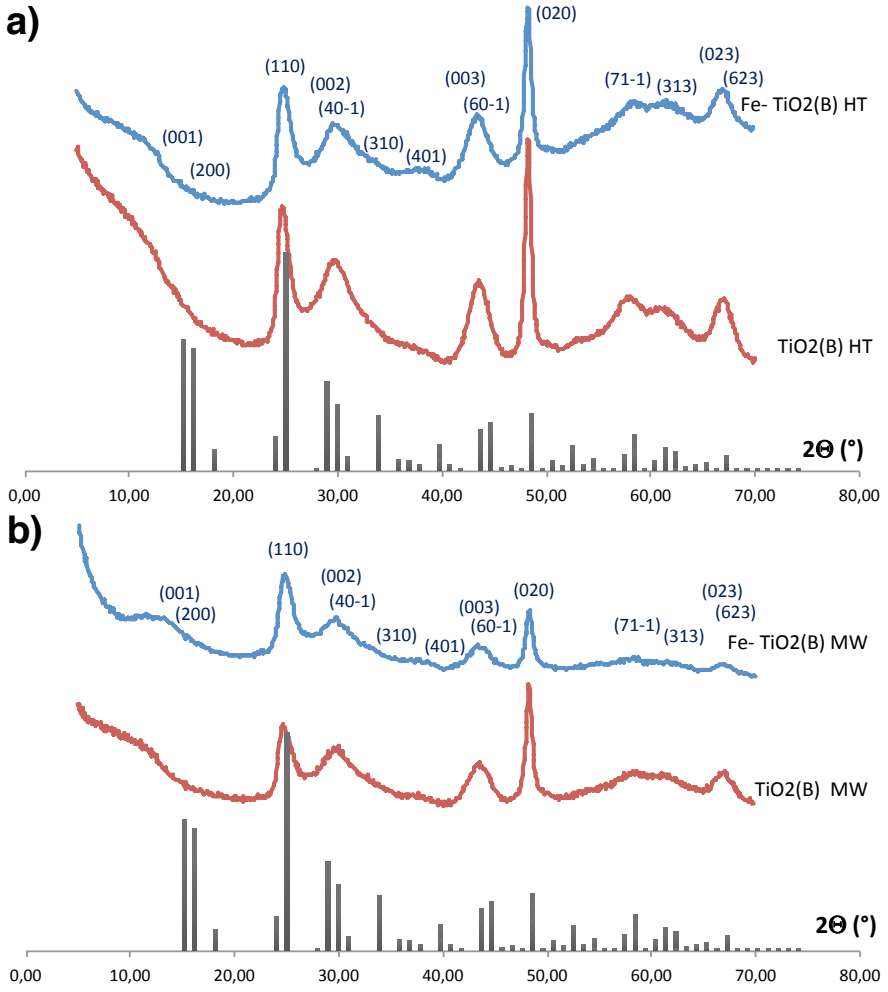

b)

- 0

a) 


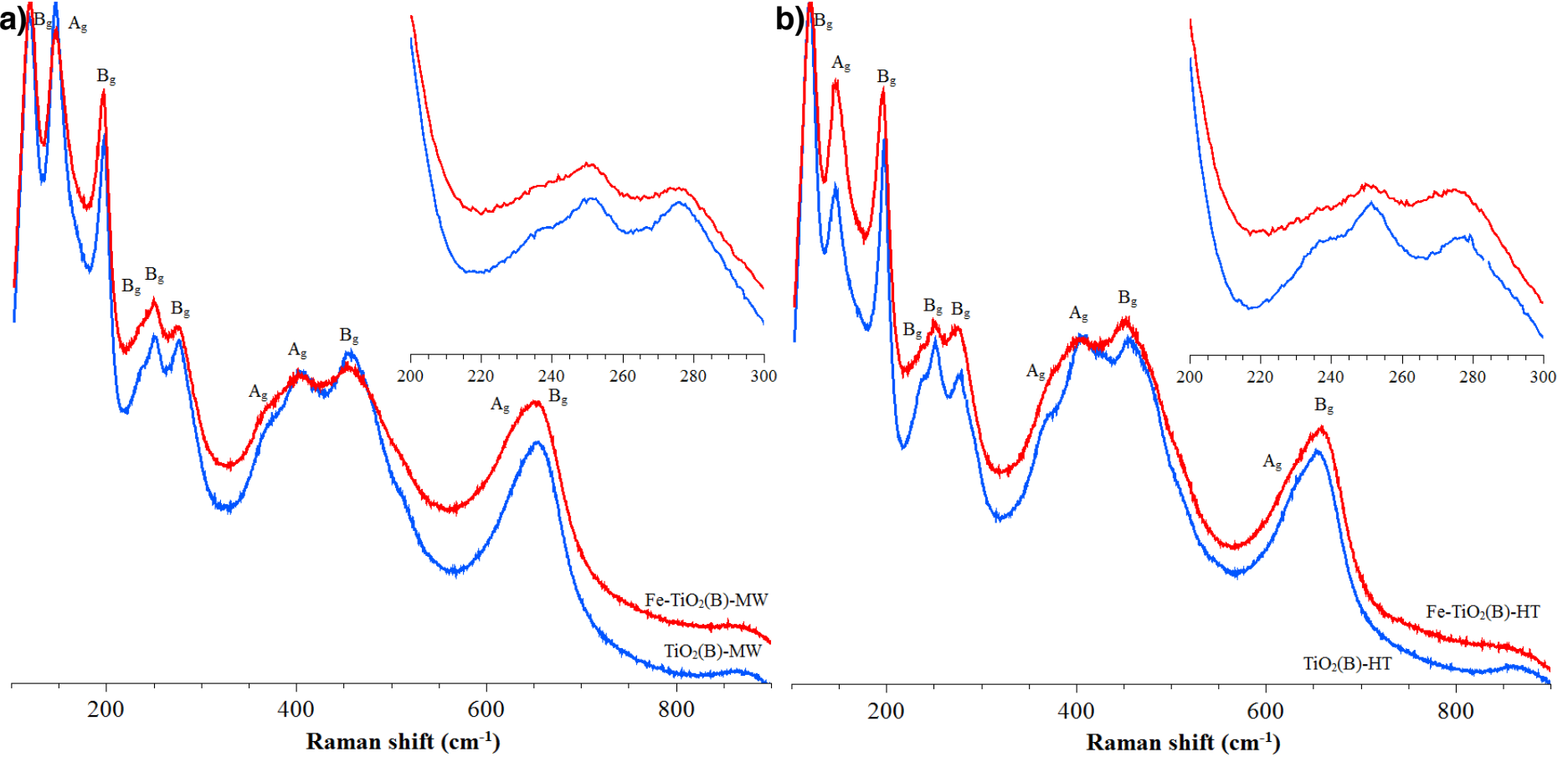




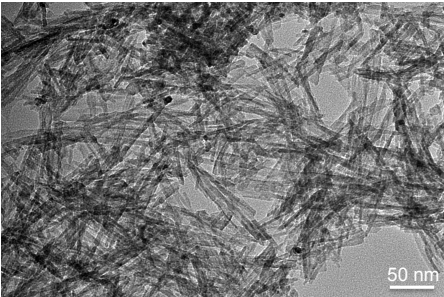




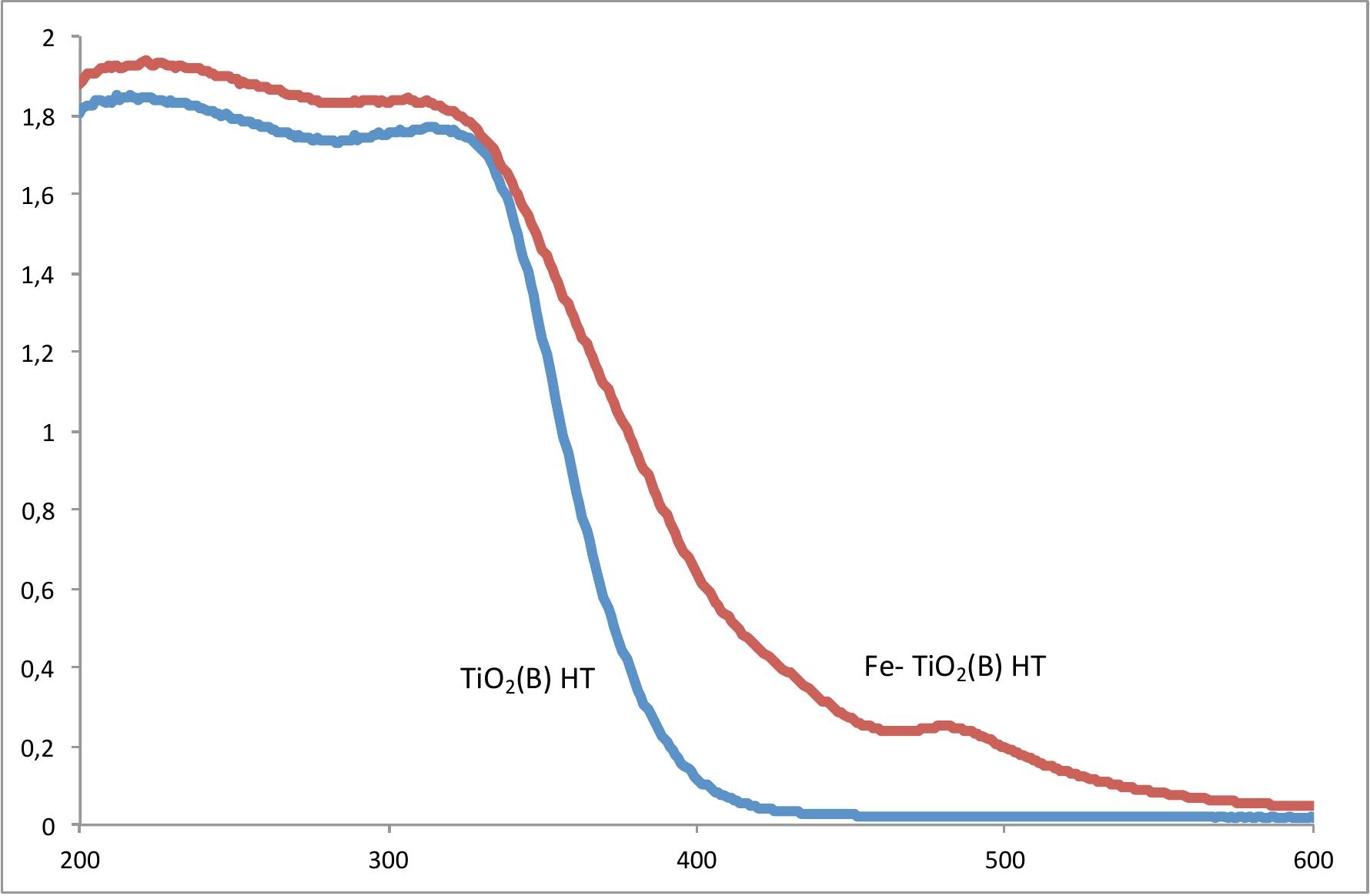




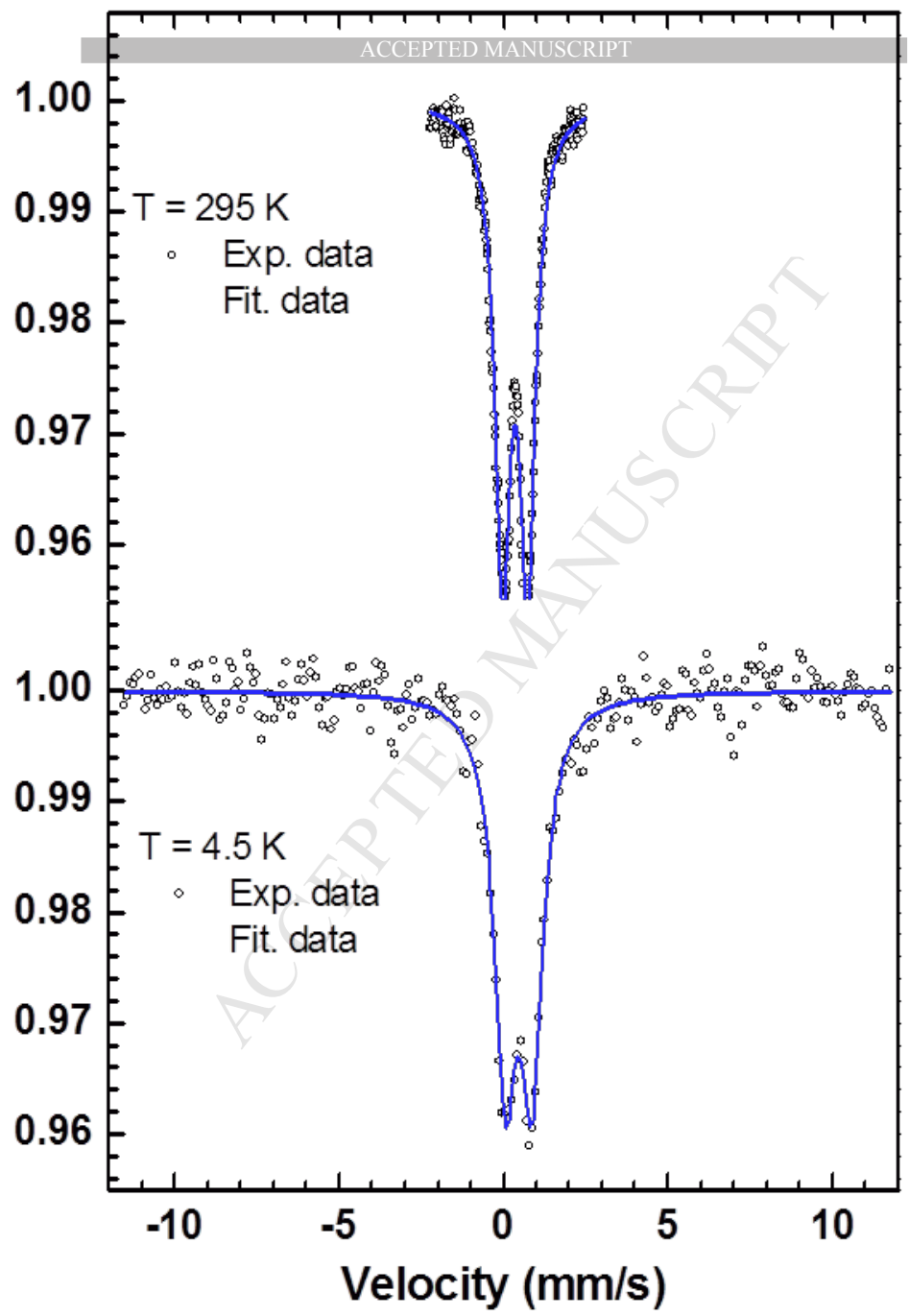




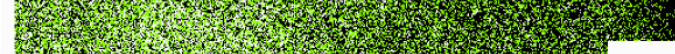

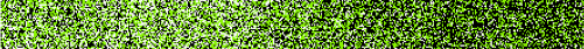
W.

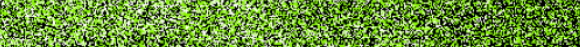
1.1.

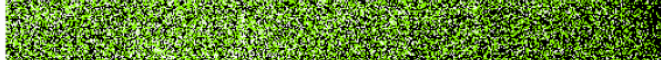
H. 1.7.

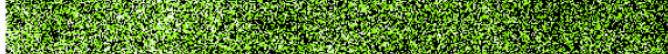
7.

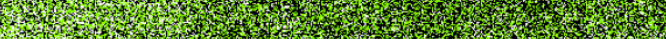

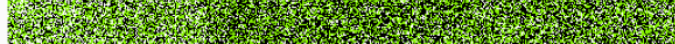
1.7. 3.1. H. F.t. m,

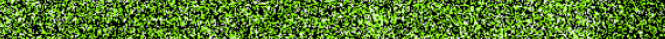
3. 1.7. W.

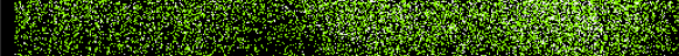

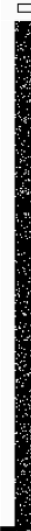

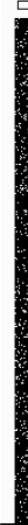$$
100 \mathrm{~nm}
$$

.

$\mathrm{Fe}$
Ti K

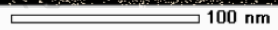


Facile synthetic route towards nanostructured $\mathrm{Fe}-\mathrm{TiO}_{2}(\mathrm{~B})$, used as negative electrode for Li-ion batteries

Remi Grosjean ${ }^{1,2,3,4}$, Marcus Fehse ${ }^{1}$, Stéphanie Pigeot-Remy ${ }^{2,3,4}$, Lorenzo Stievano ${ }^{1,5}$, Laure Monconduit $^{1,5}$, Sophie Cassaignon ${ }^{* 2,3,4,5}$

\section{Highlights:}

Highly pure $\mathrm{TiO}_{2}-\mathrm{B}$ and $\mathrm{Fe}-\mathrm{TiO}_{2}-\mathrm{B}$ were synthesized via a novel soft chemistry approach The fast microwave-assisted synthesis allows facile scale-up of the process

Microwaves reduce the reaction time by about $95 \%$ and increase cost-effectiveness

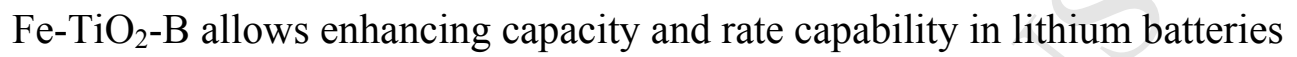

